\title{
FORMAÇÃO DE PROFESSORES: ANÁLISE DO TRABALHO PEDAGÓGICO NO PIBID - EDUCAÇÃO FÍSICA ${ }^{1}$
}

DOI: 105902/0102830819855

Data de submissão: 07-10-2015

Data de Aceite: 01-09-2016

Daiane Dalla Nora

Universidade Federal de Santa Maria dallanoradaiane@gmail.com

João Francisco Magno Ribas

Universidade Federal de Santa Maria ribasjfm@hotmail.com

Resumo: Este estudo objetiva sistematizar o trabalho pedagógico no subprojeto "Cultura esportiva da escola" do CEFD/UFSM. Foi realizado através da Pesquisa Documental, a partir da análise dos Relatórios anuais referentes aos anos 2010, 2011, 2012 e 2013. Constatou-se que o trabalho pedagógico no subprojeto aponta para a qualificação na formação de professores de Educação Física, a partir da aproximação da realidade escolar, do desenvolvimento de um trabalho coletivo, da aproximação entre teoria e prática, da produção de conhecimentos sobre a docência e da troca de experiências.

Palavras-chave: Educação Física. Ensino. Políticas públicas. Avaliação. 


\section{INTRODUÇÃO}

A busca por uma educação qualificada implica pensar na formação de professores, em especial, na formação inicial. Diante dos problemas existentes na Educação Básica e no ensino superior, como por exemplo, o índice elevado de evasão de acadêmicos de cursos de licenciatura e a precária formação inicial de professores, verifica-se que o governo elabora, em parceria com as universidades, programas que visam solucionar os problemas detectados, possibilitando aos acadêmicos de cursos de licenciatura incentivos para seguir no magistério.

O distanciamento entre a universidade e a escola de educação básica, entre teoria e prática, são problemas que levam os acadêmicos e professores recém-formados a abandonarem a profissão. Preocupações como estas levam ao desencadeamento de distintas ações, tanto por parte das universidades com reformulações do currículo de seus cursos, quanto por parte do Estado com políticas educacionais de incentivo à formação de professores.

Neste contexto, em 2007, dentre as políticas educacionais voltadas para a formação inicial de professores foi criado o Programa Institucional de Bolsa de Iniciação à Docência (PIBID), instituído pelo Ministério da Educação (MEC) e financiado pela Coordenação de Aperfeiçoamento de Pessoal de Nível Superior (CAPES). O PIBID foi criado com a finalidade de valorizar o magistério e apoiar estudantes de licenciatura plena das instituições federais e estaduais de educação superior. Um dos objetivos do PIBID é elevar a qualidade das ações acadêmicas voltadas à formação inicial de professores nos cursos de licenciatura das instituições de educação superior. O programa visa proporcionar aos futuros professores o contato com a realidade escolar e a participação em experiências metodológicas, tecnológicas e práticas docentes de caráter inovador e interdisciplinar e que busquem a superação de problemas identificados no processo de ensino-aprendizagem, com o estreitamento entre a universidade e a escola (BRASIL, 2007).

O estudo objetiva sistematizar o trabalho pedagógico no subprojeto "Cultura esportiva da escola" do CEFD/UFSM, o qual teve duração de quatro (4) anos (2010, 2011, 2012, 2013), com diversas implicações na formação inicial de professores de Educação Física. 
O interesse pela pesquisa deu-se pela necessidade de avaliação do trabalho pedagógico do subprojeto para o processo de formação de professores, buscando a qualificação do debate sobre o trabalho pedagógico no PIBID - Educação Física.

Para o estudo lançou-se mão de pesquisa documental de materiais que ainda não receberam um tratamento analítico. Segundo Sá-Silva, Almeida e Guindani (2009, p. 5), a pesquisa documental "é um procedimento que se utiliza de métodos e técnicas para a compreensão e análise de documentos dos mais variados tipos", caracterizando-se pela busca de informações em documentos que ainda não são científicos. Os documentos analisados foram os Relatórios anuais do subprojeto "Cultura esportiva da escola" referentes aos anos 2010, 2011, 2012 e 2013. A escolha pelos documentos selecionados se deu por proporcionarem as informações adequadas para cumprir responder as questões centrais da pesquisa, no que tange ao trabalho pedagógico no subprojeto.

\section{O SUBPROJETO PIBID - "CULTURA ESPORTIVA DA ESCOLA"}

As atividades do PIBID no CEFD/UFSM tiveram início no ano de 2009 com o subprojeto "Cultura esportiva da escola". Em 2011 (edital n 1/2011/CAPES), dois novos subprojetos foram incorporados: "O Ensino dos Esportes na Escola: intervenções a partir dos cenários esportivos produzidos na mídia" e "Anos Iniciais na Perspectiva Interdisciplinar". E m 2013, na reestruturação do projeto institucional da UFSM, o CEFD aprovou cinco (5) subprojetos (4 da EF e 1 interdisciplinar), sendo eles: "Educação Física na Educação Básica/segmento Educação Infantil”, “Educação Física na Educação Básica/segmento Anos Iniciais”, "Educação Física na Educação Básica/segmento Anos Finais”, "Educação Física na Educação Básica/segmento Ensino Médio" e "Trabalho pedagógico da Educação Física e da Pedagogia nos anos iniciais do Ensino Fundamental”.

A proposta do subprojeto "Cultura esportiva da escola" foi aprovada junto ao edital $n^{\circ}$ 2/2009/CAPES, com início de suas atividades em março de 2010. O subprojeto tem como objetivo a criação de um campo de atuação na docência aos futuros professores em formação inicial (acadêmicos de Educação Física do CEFD/UFSM) e formação continuada (professores que atuam nas escolas e do curso de graduação em Educação Física), 
desenvolvendo práticas e construindo estratégias educacionais na área da Educação Física escolar (SAWITZKI, 2009).

Os alunos de iniciação à docência são subsidiados por uma estrutura composta por professores do curso de graduação do CEFD e da escola, orientador do subprojeto, alunos da escola e comunidade escolar, além de materiais e equipamentos. Para Sawitzki (2009) todo esse contexto possibilita condições objetivas para que os bolsistas de iniciação à docência desenvolvam no campo de intervenção seu trabalho pedagógico, privilegiando a participação do coletivo no processo de busca de alternativas para as problemáticas existentes na escola.

Segundo o autor o subprojeto tem suas atividades desenvolvidas em quatro momentos. O primeiro momento: sondagem e diagnóstico situacional, no qual os bolsistas fazem um levantamento de informações da realidade escolar, através de observações, para construir um diagnóstico do contexto. O segundo momento: discussão no coletivo dos envolvidos no subprojeto, o qual se configura no debate em grupo sobre as variáveis observadas das práticas esportivas/formativas na escola. O terceiro momento: consiste em estruturar e desenvolver um programa de práticas esportivas/formativas na escola. O quarto momento: avaliação do subprojeto, sendo verificada a ocorrência de mudanças após as ações desenvolvidas através do planejamento previsto, bem como se as ações corresponderam aos objetivos propostos.

\section{DESVENDANDO O TRABALHO PEDAGÓGICO E SUAS IMPLICAÇÕES}

O trabalho pedagógico na perspectiva do materialismo histórico-dialético, não é apenas um tipo de prática e sim trabalho, que objetiva a produção de conhecimento. Segundo Frizzo (2008, p. 1), o conceito de trabalho pedagógico se refere a uma "noção ampliada do trabalho desenvolvido pelo professor na escola e de suas possibilidades de articulação entre a macroestrutura sócio-política e o cotidiano da docência nos espaços escolares".

O trabalho pedagógico consiste no trabalho realizado tendo como base as ciências da Educação, visando o processo de apropriação do conhecimento mais elaborado, conhecimento científico, que visa a transformação social. Dentre as características do 
trabalho pedagógico destacam-se:

a) Processo de apropriação de conhecimento que supere os métodos tradicionais e acríticos (SAVIANI, 2009, 2013);

b) Apropriação dos métodos científicos (PISTRAK, 2000);

c) Deve contemplar condições objetivas para apropriação do conhecimento, sendo este o conhecimento clássico e o mais avançado (DUARTE, 2003);

d) Deve romper e estabelecer novos caminhos com a subordinação da Educação (política educacional) à esfera de produção capitalista, necessidade de compreender seus determinantes para ser superada (FRIZZO, 2008, 2012; FREITAS, 2012);

e) Formação Omnilateral - desenvolvimento total, mais ampliado de capacidade, principalmente no plano cultural e intelectual (MANACORDA, 1991);

f) Trabalho dos professores como práxis pedagógica; Movimento dialético entre o individual e coletivo (RIBAS; FERREIRA, 2014);

g) A relação dialética entre teoria e prática; entre o individual e o coletivo; orienta-se pelos pares dialéticos objetivo/avaliação e conteúdo/método (FREITAS, 2012; SÁNCHEZ VÁZQUEZ, 2011).

Nesta perspectiva teórica, o trabalho pedagógico dá origem à produção de conhecimento e cultura pelo ser humano, é "uma prática social munida de forma e conteúdo, expressando, dentro das suas possibilidades objetivas, as determinações políticas e ideológicas dominantes em uma sociedade ou, ainda, busca a explicitação da superação destas determinações" (FRIZZO et al., 2013, p. 4).

Neste tópico será apresentada a sistematização dos dados dos relatórios que se referem ao trabalho pedagógico do PIBID - "Cultura esportiva da escola", abrangendo os anos de 2010, 2011, 2012 e 2013. Para melhor compreensão das informações sobre o trabalho pedagógico foram elencados os seguintes itens: ano e tempo de atuação, escolas, bolsistas, alunos envolvidos, oficinas desenvolvidas, atividades didáticas, produções desportivas e lúdicas, produções artístico-culturais, produções didático-pedagógicas, número de eventos, trabalhos acadêmicos e os trabalhos científicos.

Ao fazer a sistematização dos relatórios, ressalta-se que, se faz necessário a avaliação da confiabilidade, crítica do contexto, do autor, para que e para quem os mesmos foram produzidos. Sendo os relatórios destinados à avaliação do subprojeto pela CAPES é 
provável que existam preocupações para que os mesmos privilegiem os aspectos positivos, pois a CAPES é o órgão que seleciona e fomenta o programa e, nesse sentido, não seria de seu interesse uma avaliação muito comprometedora de seus objetivos.

O subprojeto teve duração de quatro anos (4), apesar de estar previsto para durar apenas dois anos, foi prorrogado por mais dois. No decorrer dos anos de 2010, 2011 e 2012, o grupo era constituído por um (1) coordenador de área, três (3) escolas estaduais de regiões distintas da cidade de Santa Maria/RS, três (3) professores supervisores e vinte e quatro (24) bolsistas. Em 2013, passaram a integrar o grupo mais uma escola municipal e uma professora supervisora, ficando cada escola com seis (6) bolsistas.

As quatro escolas vinculadas a este programas serão identificadas pelas letras $\mathrm{X}, \mathrm{Y}$, Z e W. Quanto ao número de alunos das escolas, que participaram do subprojeto tem-se: escola X - com aproximadamente 700 alunos e uma média de 400 alunos participantes do subprojeto; escola $Y$ - tem 1.700, mas apenas 600 desses são beneficiados com as atividades; escola Z - tem 600 alunos e uma média de 240 alunos participantes; e a escola W - tem 431 alunos e 200 participantes do subprojeto. Percebe-se que apesar desse subprojeto contemplar 4 escolas e um número significativo de alunos, a maioria dos alunos não estava envolvida nas atividades do subprojeto.

Quanto às oficinas e atividades didáticas desenvolvidas no subprojeto, verificou-se que eram planejadas coletivamente (bolsistas e supervisores), de acordo com a realidade de cada escola. As atividades eram elaboradas de acordo com o planejamento da própria escola, articuladas com o seu Projeto Político pedagógico (PPP), e também, de acordo com o que os bolsistas acreditavam ser importante para a realidade da escola na qual estavam inseridos. Por conta disso, constatou-se uma diversificação de conteúdos, como podemos observar no quadro 1: 


\begin{tabular}{|c|c|c|}
\hline & $\mathbf{N}^{\circ}$ OFICINAS & OFICINAS DESENVOLVIDAS/ ATIVIDADES DIDÁTICAS \\
\hline 2010 & $\begin{array}{l}\text { Não constam } \\
\text { números }\end{array}$ & $\begin{array}{l}\text { Educação Física nos Anos Iniciais, Atividades Acrobáticas e de } \\
\text { recreação, Basquetebol, Capoeira, Aeroboxe, Ginástica, Gênero e }\end{array}$ \\
\hline 2011 & 19 & $\begin{array}{l}\text { Sexualidade, Recreação, Futebol, Dança, Handebol, Esportes com } \\
\text { Raquetes, Rugby, Orientação, Jogos Tradicionais }\end{array}$ \\
\hline 2012 & 32 & $\begin{array}{l}\text { Contemporâneos, Ritmos, Futsal, Jogos Recreativos, Jogos } \\
\text { Populares, Capoeira, Atletismo, Acelera, Voleibol, Xadrez, Ping- } \\
\text { pong, Classe especial, Jogos esportivos coletivos, Circuitos e jogos }\end{array}$ \\
\hline 2013 & 38 & $\begin{array}{l}\text { motores, Habilidades motoras básicas dos esportes, Jogos } \\
\text { cooperativos, Psicomotricidade e cooperação, Esportes adaptados, } \\
\text { Jogos cooperativos e competitivos, Jogos educativos, Crescimento }\end{array}$ \\
\hline TOTAL & 89 & $\begin{array}{l}\text { e desenvolvimento motor, Dança gaúcha, Esporte da escola, } \\
\text { Ludicidade e movimento, Oficina do corpo. }\end{array}$ \\
\hline
\end{tabular}

Quadro 1 - Oficinas/atividades didáticas.

As oficinas trabalhadas no subprojeto tinham tempo de duração que variava de acordo com a necessidade de compreensão dos alunos. Além disso, houve um avanço no que se refere à diversificação dos conteúdos. O subprojeto demonstrou ser um diferencial ao possibilitar aos alunos a vivência e a experiência com as diversas manifestações culturais.

As oficinas/atividades didáticas abordavam diferentes conteúdos da Educação Física como: danças, jogos, lutas, ginástica, entre outros, não reforçando assim a hegemonia do esporte. Como afirma Soares (1996, p. 11) que a contribuição da Educação Física é a de colocar os alunos diante desse patrimônio da humanidade, pois "historicamente a Educação Física ocidental moderna tem ensinado o jogo, a ginástica, as lutas, a dança, os esportes. Poderíamos afirmar então que estes são conteúdos clássicos”. A autora expressa ainda que é necessário que essas "atividades codificadas pelo homem em sua história devem valer-se, criativamente, de metodologias que encerrem valores mais solidários, que apontem para uma saudável relação entre indivíduo e sociedade e vice-versa" (p. 10).

Com base nos pontos de avaliação descritos do relatório do subprojeto (indicador da atividade, objetivo da atividade, descrição sucinta da atividade, resultados alcançados), constatou-se que a maioria das oficinas estavam condizentes no que se refere ao conteúdo e a metodologia.

No que se refere às produções desportivas/lúdicas foram realizadas um total de 22 , 
podendo-se considerar um número significativo, como se observa no quadro 2 :

\begin{tabular}{|c|c|l|}
\hline $\mathbf{2 0 1 0}$ & $\begin{array}{c}\text { PRODUÇÕES } \\
\text { DESPORTIVAS } \\
\text { E LÚDICAS }\end{array}$ & \multicolumn{1}{|c|}{ TIPO DE PRODUÇÃO DESPORTIVA/LÚDICA } \\
\hline $\mathbf{2 0 1 1}$ & 5 & $\begin{array}{l}\text { Torneio para os pais, Interséries futsal masculino, Interséries } \\
\text { Voleibol Feminino, Gincana da Semana da criança, Recreio } \\
\text { Dirigido. }\end{array}$ \\
\hline $\mathbf{2 0 1 2}$ & 6 & $\begin{array}{l}\text { Interséries Escola Z, Copa de Integração Escola W, Mini Torneio } \\
\text { de xadrez Escola Y, Mini Atletismo no CEFD/UFSM-Escola Y, } \\
\text { Atividades Integrativas Dia dos Pais-Escola X. }\end{array}$ \\
\hline $\mathbf{2 0 1 3}$ & 6 & $\begin{array}{l}\text { Seminário de Jovens, Semana da criança, Torneio de Pais,Jogos } \\
\text { de integração Escola Y, Gincana entre alunos do Projeto, } \\
\text { Interséries da Escola Z. }\end{array}$ \\
\hline TOTAL & $\mathbf{2 2}$ & $\begin{array}{l}\text { Gincana Interdisciplinar de Halloween, Gincana Pedagógica de } \\
\text { Torneio comemorativo Dia dos Pais, Semana da criança. }\end{array}$ \\
\hline
\end{tabular}

Quadro 2 - Produção Desportiva/lúdica.

Durante a inserção dos alunos bolsistas do subprojeto no ambiente escolar, foram desenvolvidas várias produções artístico-culturais, que tinham como temáticas as manifestações culturais relacionadas com datas comemorativas, conforme quadro 3 . Essas produções foram elaboradas juntamente com a comunidade escolar. Deste modo, observase que alunos bolsistas participaram na construção das produções artístico-culturais e como colaboradores nos eventos das escolas. Estes eventos eram produzidos tanto para os alunos na escola, quanto para os pais e a comunidade em geral. 


\begin{tabular}{|c|c|c|}
\hline & $\begin{array}{l}\text { PRODUÇÕES } \\
\text { ARTÍSTICO- } \\
\text { CULTURAIS }\end{array}$ & TIPO DE PRODUÇÃO ARTÍSTICO-CULTURAIS \\
\hline 2010 & 6 & Festa Junina, Desfile da Semana da Pátria, \\
\hline 2011 & 8 & $\begin{array}{l}\text { Festa Junina, Festa Agostina Escola Z, Festival da Pandorga, } \\
\text { Festa Junina Escola Y, Atividades Natalinas Escola Y, Festa } \\
\text { Junina Escola X, Desfile cívico, Desfile da Pátria Escola Y, } \\
\text { Desfile } 7 \text { de setembro Escola X. }\end{array}$ \\
\hline 2012 & 9 & $\begin{array}{l}\text { Festa Junina Escola X, Festa Julina escola Y, Dia dos Pais } \\
\text { Escola Y, Festa Natalina Escola Y, Festa Agostina Escola Z, Dia } \\
\text { das Mães Escola Z, Semana Farroupilha, Desfile da Pátria } \\
\text { Escola X, Desfile } 7 \text { de Setembro. }\end{array}$ \\
\hline 2013 & 5 & $\begin{array}{l}\text { Atividades Lúdicas na Festa Junina, Participação nas atividades } \\
20 \text { de Setembro, Presépio vivo, Passeio clube Dores. }\end{array}$ \\
\hline TOTAL & 28 & \\
\hline
\end{tabular}

Quadro 3- Produção Artístico - Cultural.

Quanto às produções didático-pedagógicas foram realizadas: uma Mostra Pedagógica - apresentação de banner, um Minicurso de Iniciação ao Desporto Orientação, um passeio a Feira do Livro - jornais produzidos na escola, uma Profitecs e trinta e nove (39) Planos de aula.

Através do subprojeto os bolsistas participaram de eventos internacionais, nacionais e regionais como, por exemplo, a Jornada Acadêmica Integrada - promovida anualmente pela UFSM, congressos da área, encontros de todos os PIBIDs da UFSM, seminários, totalizando nesses 4 anos de subprojeto um número de 24 eventos, sendo a maioria (23) de abrangência regional.

O subprojeto também gerou várias produções bibliográficas , que ocorrem numa forma crescente em meios de divulgação mais qualificados. De 2010 a 2013, foram produzidos Trabalho de Conclusão de curso- TCC's, livros, capítulos de livros, além de publicação de 
artigos em revista especializada da área, de trabalhos completos, de resumos expandidos e de resumos simples, conforme quadro 4. Isso demostra que o subprojeto contribuiu para a realização de pesquisas, debates, leituras e reflexões sobre o trabalho pedagógico da Educação Física escolar e a formação inicial, apontando as dificuldades encontradas no cotidiano escolar, no currículo do curso, na relação teoria e prática e no planejamento da Educação Física escolar.

\begin{tabular}{|c|c|c|c|c|c|c|c|c|}
\hline & \multicolumn{7}{|c|}{ PRODUÇÃO ACADÊMICO/INTELECTUAL } \\
\hline ANO & $\begin{array}{c}\text { TCC } \\
\text { 's }\end{array}$ & $\begin{array}{c}\text { MONO } \\
\text { GRAFIA } \\
\text { S }\end{array}$ & $\begin{array}{c}\text { LIVRO } \\
\text { S }\end{array}$ & $\begin{array}{c}\text { CAPÍTUL } \\
\text { OS }\end{array}$ & $\begin{array}{c}\text { ARTIGO } \\
\text { S }\end{array}$ & $\begin{array}{c}\text { TRABALHO } \\
\text { S } \\
\text { COMPLETO } \\
\text { S }\end{array}$ & $\begin{array}{c}\text { RESUMOS } \\
\text { EXPANDID } \\
\text { OS }\end{array}$ & $\begin{array}{c}\text { RESUMOS } \\
\text { SIMPLES }\end{array}$ \\
\hline $\mathbf{2 0 1 0}$ & 0 & 0 & 0 & 0 & 0 & 0 & 18 & 1 \\
\hline $\mathbf{2 0 1 1}$ & 1 & 0 & 0 & 0 & 3 & 0 & 13 & 0 \\
\hline $\mathbf{2 0 1 2}$ & 2 & 1 & 0 & 0 & 2 & 0 & 20 & 4 \\
\hline $\mathbf{2 0 1 3}$ & 5 & 2 & 1 & 4 & 0 & 7 & 9 & 7 \\
\hline $\begin{array}{c}\text { TOTA } \\
\text { L }\end{array}$ & $\mathbf{8}$ & $\mathbf{3}$ & $\mathbf{1}$ & $\mathbf{4}$ & $\mathbf{5}$ & $\mathbf{7}$ & $\mathbf{6 0}$ & $\mathbf{1 2}$ \\
\hline
\end{tabular}

Quadro 4 - Produção acảdêmico/intelectual.

Para o desenvolvimento do subprojeto, foram adquiridos alguns bens patrimoniais/ materiais didáticos como: bomba de encher bolas, bola de futsal, voleibol, handebol, basquete, colchonetes, bolas de borracha, bolas de ping-pong, cones, cordas, redes, mesas e raquetes de ping-pong, entre outros. A seleção dos materiais comprados era realizada pelos acadêmicos e supervisores, pois os mesmos conheciam a realidade da escola. Os materiais comprados ficaram para a escola e tiveram o objetivo de qualificar as atividades e de melhorar o trabalho pedagógico.

Quantos aos impactos, definidos no Relatório do PIBID - "Cultura esportiva da escola" como os efeitos produzidos pelo subprojeto que tenham gerado modificações em algum aspecto do campo de atuação, destacam-se os efeitos das ações/atividades do subprojeto na formação de professores, nas licenciaturas envolvidas, na educação básica e na pósgraduação, como é destacado a seguir. 
Na formação inicial: Os relatórios do subprojeto apontam que, através da inserção dos acadêmicos participantes do subprojeto, foi possível realizar reflexões sobre a identidade do professor e seu papel no ensino da Educação Física. Os acadêmicos, aprenderam a ser professor, inseridos na realidade da escola e não mais apenas através das disciplinas curriculares, das práticas de ensino e de estágios supervisionados que já se mostraram insuficientes. Com a inserção dos alunos no contexto escolar foi possível estabelecer relações entre estes e os professores que trabalhavam nas escolas, ocorrendo trocas significativas, além de discussões com colegas dos acadêmicos do subprojeto, porque os bolsistas, ao conhecerem a escola, têm oportunidades de falar para seus colegas sobre um real estabelecimento de ensino.

Percebeu-se a criação de um espaço de estudos e reflexão do trabalho pedagógico da Educação Física. O subprojeto possibilitou a ampliação do conhecimento e desenvolvimento de um trabalho mais crítico, à medida que os acadêmicos passaram a analisar, investigar, refletir e modificar o seu trabalho pedagógico. Logo, a experiência adquirida no contexto escolar oferecida pelo subprojeto, aliada ao aporte teórico oferecido pela universidade, supervisionado por um professor que atua no contexto escolar, constitui situação primordial para a problematização e à construção de conhecimentos acerca do processo educativo no âmbito da formação inicial de professores de Educação Física. De acordo com Ribas e Ferreira (2013),

[...] programas como o PIBID - Programa Institucional de Bolsa de Iniciação à docência, desenvolvidos em sinergia com as atividades de graduação, potencializam as condições de os acadêmicos constituírem-se professores. As ações de conhecer, planejar, implementar e avaliar atividades, integrando-se a uma proposta de trabalho pedagógico na escola, exigem dos acadêmicos que se permitam o lugar de professores, antecipando seu trabalho futuro e, assim, produzindo conhecimentos significativos para sua pertença à profissão (RIBAS; FERREIRA, 2013,135).

Percebe-se que o trabalho pedagógico no subprojeto supracitado aponta para aproximar os aspectos teóricos tratados na formação inicial com a realidade escolar. Para Gamboa (1995, p. 1) "Teoria e prática são duas categorias que indicam sempre uma relação. Entretanto, a literatura nem sempre apresenta consenso na interpretação dessa relação. Algumas tendências defendem o primado da teoria perante a prática; outras, o primado 
da prática que confere validez à teoria". Ressalta-se como ponto positivo do subprojeto a aproximação entre teoria e prática, pois possibilitou a inserção na escola juntamente com um significativo embasamento teórico.

Contribuições para a licenciatura: Conforme os relatórios, a Educação Física, assim como as demais licenciaturas, em sua grade curricular, não consegue contemplar todas as necessidades dos acadêmicos, fazendo com que estes busquem outros meios para as demandas provenientes da escola. Nesse sentido, o subprojeto contribuiu para a formação inicial dos bolsistas de iniciação à docência, possibilitando um rico espaço de vivências e experiências profissionais significativas que acabam enriquecendo a formação inicial desses alunos. Para Taffarel (1993) assim como as demais licenciaturas, a formação inicial em Educação Física apresenta problemas curriculares como a dissociação entre teoria e prática.

Educação básica: Os relatórios assinalam que o subprojeto possibilitou também a formação continuada dos professores supervisores, contribuindo para a reconstrução de seu próprio trabalho pedagógico, ajudando a preencher as lacunas deixadas na formação inicial desses professores supervisores. Uma vez que, atualmente os professores da rede pública não têm garantido o direito à formação continuada pelos órgãos públicos responsáveis, sendo os professores cobrados para que se qualifiquem, e responsabilizados pelo fracasso da educação (MARIN et al., 2011).

Pós-graduação: Segundo os relatórios, alunos egressos do subprojeto foram aprovados em cursos de Pós-Graduação, em nível de especialização, mestrado e doutorado. Além do mais, observou-se o aumento de pesquisas que estão ocorrendo relacionadas ao subprojeto, à iniciação à docência e formação de professores. Para Ribas e Ferreira (2013, p. 136) "os professores envolvidos nos subprojetos PIBID trabalham em programas de pós-graduação stricto sensu e latu sensu, podendo articular, assim, os projetos com as temáticas de interesse na pós-graduação".

Dificuldades encontradas: Os relatórios apresentam algumas dificuldades pelos bolsistas principalmente quanto à questão disciplinar dos alunos da escola, pois quase sempre se encontravam com atitudes inadequadas de comportamento, comprometendo o andamento da aula; à organização dos horários do bolsista com os horários da escola; ao espaço físico não adequado; à desmotivação de alguns alunos da escola; ao pouco contato 
com os diferentes conteúdos, dificuldade em realizar as atividades propostas e à coerência em manter uma abordagem, devido à falta de experiência.

Indicadores de avaliação: Os indicadores de avaliação criados englobavam as observações, relatos dos bolsistas e dos professores das escolas, além dos memoriais descritivos individuais e relatórios finais do subprojeto. As avaliações das escolas foram realizadas por diversas ferramentas como questionários, rodas de conversa, grupo de estudos e fichas avaliativas. Segundo Rosa (2014, p. 93), a partir desses indicadores, ocorreu a expansão e a consolidação do PIBID, com "[...]a abertura de novos editais, sua extensão às demais licenciaturas; a abertura para as IES privadas submeterem propostas; execução de todos os processos de seleção por editais e a promulgação da Lei $n^{\circ} 12.796 / 2013$, que insere na LDB 9.394/96, um adendo instituindo o PIBID como um programa contínuo".

Críticas e sugestões de melhoramento do programa na Instituições de Ensino Superior - IES e na CAPES: De acordo com os relatórios, as principais sugestões para melhoria do programa junto a CAPES referem-se as questões que envolvem o aumento de bolsas de iniciação à docência e a disseminação do programanas IES também à outras licenciaturas. Quanto as avaliações, de cunho quantitativo, colocadas pelas IES e CAPES, sugeriu-se que para qualificar o subprojeto é necessária uma avaliação de cunho mais qualitativa do processo, para assim conferir maior responsabilidade ao coordenador, supervisores, bolsistas e escolas envolvidas. Percebe-se nitidamente a necessidade de uma avaliação mais consistente do subprojeto e do PIBID enquanto política educacional.

\section{CONSIDERAÇÕES FINAIS}

Evidenciou-se, a partir do exposto, os principais aspectos que estruturam o subprojeto, que indicam elementos que poderão favorecer a formação inicial dos Bolsistas de Iniciação à Docência. Constatou-se que as atividades do subprojeto PIBID tem se constituído em um relevante espaço de formação complementar a formação inicial, orientado por professores da graduação e professores que atuam em escolas, estacam-se as seguintes ações: sondagem-diagnóstico, estudo, planejamento, proposições (propostas de trabalho), intervenções e avaliações. Estes espaços de aprendizagem, que não eram sequenciais 
mas dinâmicos, se deram num contexto concreto, com uma proposta concreta, que era vivenciada pelos bolsistas do início ao fim.

O subprojeto PIBID - "Cultura esportiva da escola" constitui-se como rico espaço de formação inicial e continuada, pois ele insere o acadêmico na escola no papel de professor, criando estratégias para enfrentar esses problemas impostos pela realidade concreta, através de um conjunto de ações que mediam o processo de interação entre escolas, universidade e comunidade. O trabalho pedagógico no PIBID aponta para a qualificação na formação dos bolsistas envolvidos no subprojeto, a partir da aproximação da realidade escolar, do desenvolvimento de um trabalho coletivo, da aproximação entre teoria e prática, da produção de conhecimentos sobre a docência e da troca de experiências. Mas o PIBID enquanto política educacional? Quais suas repercussões para a formação de professores de Educação Física? Não seria essa política uma ação compensatória que acaba preenchendo lacunas da formação inicial? Uma política de adesão individual, própria da política neoliberal, que prejudica e desmobiliza ações coletivas desqualificando a formação de professores de Educação Física? 


\section{REFERÊNCIAS}

BRASIL. Portaria n $^{\circ}$. 38/2007, de 12 de dezembro de 2007. Dispõe sobre o Programa de Bolsa Institucional de Iniciação à Docência - PIBID. Brasília, 2007. Disponível em:<http:// www.capes.gov.br/images/stories/download/legislacao/Portaria_Normativa_38_PIBID. pdf>. Acesso em 03 fev. 2015.

DUARTE, Newton. Sociedade do conhecimento ou sociedades das ilusões? Quatro ensaios Crítico-dialéticos em filosofia da educação. Campinas, São Paulo. Autores Associados, 2003.

FREITAS, Luis Carlos. Crítica da Organização do Trabalho Pedagógico e da Didática. $11^{\text {a }}$ ed. Campinas, São Paulo: Papirus, 2012.

FRIZZO, Giovanni. O trabalho pedagógico como referência para a pesquisa em educação física. Pensar a prática, Goiás, v. 11, n. 2, p. 159-167, mai./ago. 2008.

\section{A Organização do Trabalho Pedagógico da Educação Física na escola}

capitalista. 2012. 264 f. Tese (Doutorado em Ciências do Movimento) - Universidade Federal do Rio Grande do Sul, Porto Alegre, 2012.

; RIBAS, J. F. M.; FERREIRA, L. S. A relação trabalho-educação na organização do trabalho pedagógico da escola capitalista. Revista Educação, Santa Maria, v. 38, n. 3, 2013. Disponível em: <http://cascavel.ufsm.br/revistas/ojs-2.2.2/index.php/reveducacao/ article/view/8987/pdf>. Acesso em: 20 nov. 2013.

MANACORDA, Mario Aligheiro. Marx e a pedagogia moderna. São Paulo: Cortez: Autores Associados, 1991. 
MARIN, Elizara Carolina. et al. Formação Continuada em Educação Física: Relação entre Mundo do Trabalho, Políticas Educacionais e Educação. Revista Movimento, Porto Alegre/RS, v. 17, n. 2 (2011).

PISTRAK, Moisey Mikhaylovich. Fundamentos da escola do trabalho. São Paulo: Expressão Popular, 2000.

RIBAS, João Francisco Magno; FERREIRA, Liliana Soares. À guisa de um posfácio: uma resenha sobre o trabalho pedagógico e o PIBID. In: SAWITZKI, R. L.; RIBAS, J. F. M. (Org.). Cultura esportiva da escola. São Leopoldo: Oikos, 2013. p. 135-140.

- Trabalho de professores na escola como práxis pedagógica. Movimento, Porto Alegre, v. 20, n. 01, p. 125-143, jan/mar de 2014.

ROSA, Cristian Leandro Lopes. PIBID: Formação Continuada para Professores de Educação Física. 2014. 114 f. Dissertação (Mestrado em Educação) - Universidade Federal de Pelotas, Pelotas, 2014.

SÁ-SILVA, Jackson Ronie; ALMEIDA, Cristóvão Domingos; GUINDANI, Joel Felipe. Pesquisa documental: pistas teóricas e metodológicas. Revista Brasileira de História \& Ciências Sociais. São Leopoldo. Ano I, n. I, Jul. 2009. Disponível em: <http://www.rbhcs. com/index_arquivos/Artigo.Pesquisa\%20documental.pdf>. Acesso em: 13 jan. 2015.

SÁNCHEZ GAMBOA, Silvio. Teoria e da prática: uma relação dinâmica e contraditória. Revista Motrivivência. Florianópolis-UFSC, ano VII, n. 8, p. 31-45, dez., 1995. Disponível em: $\quad$ <https://periodicos.ufsc.br/index.php/motrivivencia/article/view/22595/20588>. Acesso em: 22 nov. 2014.

SÁNCHEZ VÁZQUEZ, Adolfo. Filosofia da Práxis. 2.ed. São Paulo: Expressão 
Popular, Brasil, 2011.

SAVIANI, Dermeval. Pedagogia histórico-crítica: primeiras aproximações. 11. ed. Campinas, São Paulo: Autores Associados, 2013.

Escola e Democracia. 41. ed. Campinas, São Paulo: Autores Associados, 2009.

SAWITZKI, Rosalvo Luis. Detalhamento do Subprojeto Cultura Esportiva da Escola. Programa Institucional de Bolsa de Iniciação à Docência - PIBID. Santa Maria, RS, 2009.

SOARES, Carmen Lúcia. Educação Física Escolar: conhecimento e especificidade. Revista Paulista Educação Física, São Paulo, supl.2, p.6-12, 1996. Disponível em:<http:// citrus.uspnet.usp.br/eef/uploads/arquivo/v10\%20supl2\%20artigo1.pdf>. Acesso em: 03 jan. 2015.

TAFFAREL, Celi Zulke. A formação profissional em educação: o processo de trabalho pedagógico e o trato com o conhecimento no curso de educação física. $230 f$. 1993. Tese (Doutorado em Educação) - Universidade Estadual de Campinas, Faculdade de Educação, UNICAMP, 1993. 


\section{TEACHER EDUCATION: ANALYSIS OF EDUCATIONAL WORK IN PIBID - PHYSICAL EDUCATION}

Abstract: This study aims to systematize the pedagogical work in the subproject "Sports culture school" of CEFD/UFSM. It was performed by Document Search from the analysis of the annual reports for the years 2010, 2011, 2012 and 2013. It was found that the pedagogical work in the subproject points to the qualification in the training of physical education teachers from the approach the school reality, the development of a collective work, bringing together theory and practice, the production of knowledge about teaching and exchange of experiences.

Keywords: Physical Education. Teaching. Public policies. Evaluation.

\section{EDUCACIÓN DOCENTE: ANÁLISIS DE TRABAJO EDUCATIVO EN PIBID - EDUCACIÓN FÍSICA}

Resumen: Este estudio tiene como objetivo sistematizar el trabajo pedagógico en el subproyecto "Cultura esportiva da escola" del CEFD/UFSM. Fue realizado a través de Investigación Documental, basado en análisis de los informes anuales correspondientes a los años 2010, 2011, 2012 y 2013. Se encontró que el trabajo pedagógico en el subproyecto está direccionado hacia la calificación en la formación de profesores de educación física, a partir de la aproximación a la realidad escolar, el desarrollo de un trabajo colectivo, el acercamiento entre teoría y la práctica, la producción de conocimiento sobre la enseñanza y el intercambio de experiencias.

Palabras - clave: Educación Física. Ensenanza. Políticas públicas. Evaluación. 